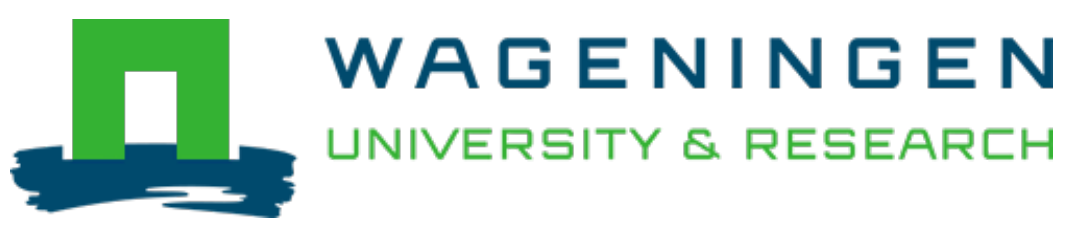

\title{
Population- and Species-Based Variation of Webworm-Parasitoid Interactions in Hogweeds (Heracelum spp.) in the Netherlands
}

\author{
Environmental Entomology \\ Harvey, Jeffrey A.; Ode, Paul J.; Gols, Rieta \\ https://doi.org/10.1093/ee/nvaa052
}

This article is made publicly available in the institutional repository of Wageningen University and Research, under the terms of article $25 \mathrm{fa}$ of the Dutch Copyright Act, also known as the Amendment Taverne. This has been done with explicit consent by the author.

Article 25 fa states that the author of a short scientific work funded either wholly or partially by Dutch public funds is entitled to make that work publicly available for no consideration following a reasonable period of time after the work was first published, provided that clear reference is made to the source of the first publication of the work.

This publication is distributed under The Association of Universities in the Netherlands (VSNU) 'Article $25 \mathrm{fa}$ implementation' project. In this project research outputs of researchers employed by Dutch Universities that comply with the legal requirements of Article $25 \mathrm{fa}$ of the Dutch Copyright Act are distributed online and free of cost or other barriers in institutional repositories. Research outputs are distributed six months after their first online publication in the original published version and with proper attribution to the source of the original publication.

You are permitted to download and use the publication for personal purposes. All rights remain with the author(s) and / or copyright owner(s) of this work. Any use of the publication or parts of it other than authorised under article $25 \mathrm{fa}$ of the Dutch Copyright act is prohibited. Wageningen University \& Research and the author(s) of this publication shall not be held responsible or liable for any damages resulting from your (re)use of this publication.

For questions regarding the public availability of this article please contact openscience.library@,wur.nl 


\title{
Population- and Species-Based Variation of Webworm- Parasitoid Interactions in Hogweeds (Heracelum spp.) in the Netherlands
}

\author{
Jeffrey A. Harvey, ${ }^{1,2,5}$ Paul J. Ode, ${ }^{3}$ and Rieta Gols ${ }^{4}$ \\ 1Department of Terrestrial Ecology, Netherlands Institute of Ecology, Droevendaalsesteeg 10, 6700 AB Wageningen, The \\ Netherlands, ${ }^{2}$ Department of Ecological Sciences, Section Animal Ecology, VU University Amsterdam, De Boelelaan 1085, 1081 HV \\ Amsterdam, The Netherlands, ${ }^{3}$ Graduate Degree Program in Ecology, Department of Bioagricultural Sciences and Pest Management, \\ Colorado State University, Fort Collins, C0, 80523-1177, 'Laboratory of Entomology, Wageningen University, Droevendaalsesteeg 1, \\ 6700 EH Wageningen, The Netherlands, and ${ }^{5}$ Corresponding author, e-mail: j.harvey@nioo.knaw.nl
}

Subject Editor: Jared Ali

Received 11 February 2020; Editorial decision 16 April 2020

\begin{abstract}
In three Dutch populations of the native small hogweed (Heracleum sphondylium L. [Apiales: Apiaceae]), and one of the invasive giant hogweed ( $H$. mantegazzianum Sommeier \& Levier [Apiales: Apiaceae]), interactions between a specialist herbivore, the parsnip webworm (Depressaria radiella), and its associated parasitoids were compared during a single growing season. We found host plant species-related differences in the abundance of moth pupae, the specialist polyembryonic endoparasitoid, Copidosoma sosares, the specialist pupal parasitoid, Barichneumon heracliana, and a potential hyperparasitoid of $C$. sosares, Tyndaricus scaurus Walker (Hymenoptera: Encyrtidae). Adult $D$. radiella body mass was similar across the three small hogweed populations, but moths and their pupal parasitoid $B$. heracliana were smaller when developing on giant than on small hogweeds where the two plants grew in the same locality (Heteren). Mixed-sex and all-male broods of $C$. sosares were generally bigger than allfemale broods. Furthermore, adult female $C$. sosares were larger than males and adult female mass differed among the three small hogweed populations. The frequency of pupal parasitism and hyperparasitism also varied in the different $H$. sphondylium populations. These results show that short-term (intra-seasonal) effects of plant population on multitrophic insects are variable among different species in a tightly linked food chain.
\end{abstract}

Key words: co-evolution, Copidosoma sosares, Depressaria radiella, fitness, parsnip webworm

In nature, plants do not grow in isolation, but are involved in an array of interactions with other organisms. Many of these interactions are highly intimate, because plants provide other animals, such as herbivores, with food and shelter, and natural enemies of the herbivores, such as predators, with prey. When the frequency of these interactions is high, it can drive strong reciprocal selection for the evolution of adaptive traits in both the plant and the animals that are associated with it (Karban et al. 1999). These traits include the expression of defenses in the plants to reduce the harmful impact of the herbivores, and counter-strategies in the herbivores that enable them to exploit plant tissues (Karban and Baldwin 1997, Fürstenberg-Hägg et al. 2013). In natural enemies, it may lead to the expression of traits that enable them to use plant cues more effectively, thereby increasing their ability to catch prey or parasitize hosts (Heil 2014). Over time, this strong selection among different members of a food chain may drive the evolution of specialism among the various species involved. Evidence suggests that the vast majority of insect herbivores, for example, are specialized in attacking plants with phylogenetically conserved secondary (=defensive) metabolites, and even specific plant tissues, such as young shoots, flowers, or seeds (Loxdale et al. 2011). In turn, some natural enemies, such as parasitoid wasps, are highly specialized in attacking only one or a few species of hosts (Godfray 1994).

The small hogweed (Heracleum sphondylium L. [Apiales: Apiaceae]) is an abundant plant that is native to Eurasia and grows in discrete populations across its broad range (Zych 2007). This species and related plants in the Apiaceae, such as wild parsnip, produce defensive secondary metabolites called 'furanocoumarins' (Zangerl and Nitao 1998). These chemicals are phototoxic against a range of insect and mammalian herbivores (Berenbaum 1995). The main herbivore of small hogweed is the parsnip webworm, Depressaria radiella Goeze (Lepidoptera: Depressariidae, Fig 1a), which is specialized in feeding on developing flowers and fruits of hogweeds and related plant species 
(a)

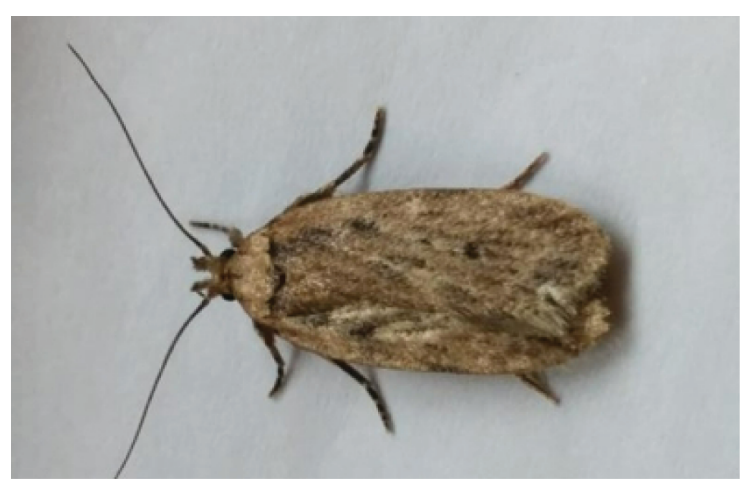

(b)

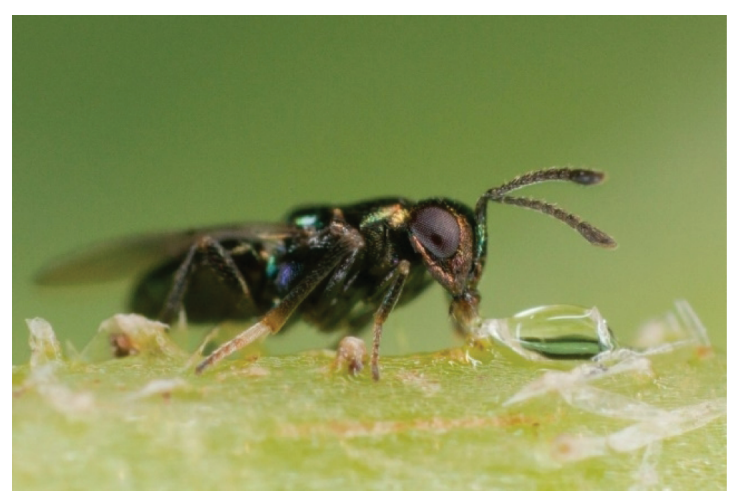

(c)

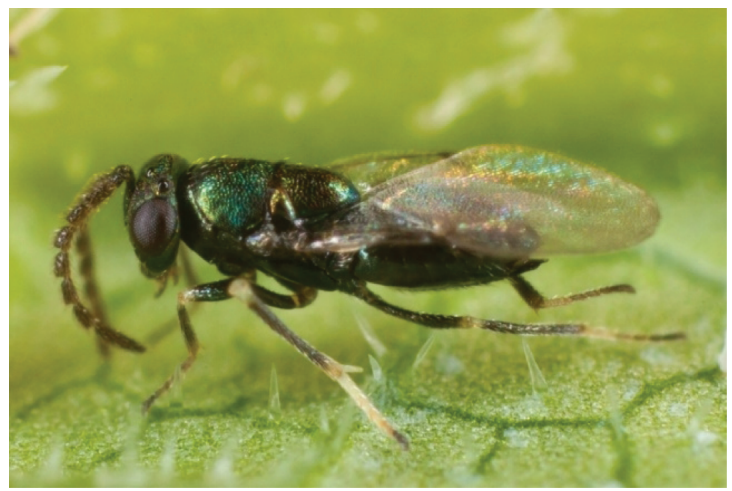

(d)

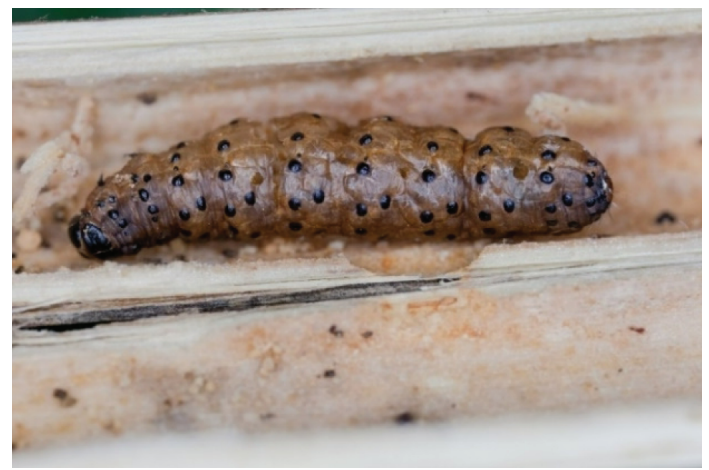

(f)

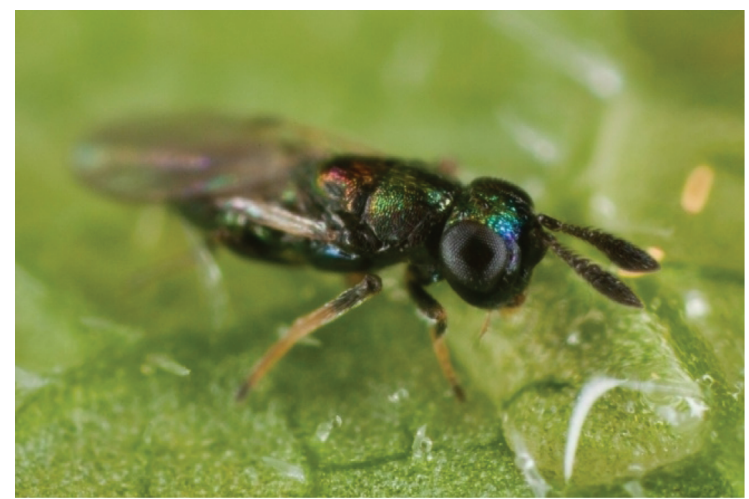

(e)

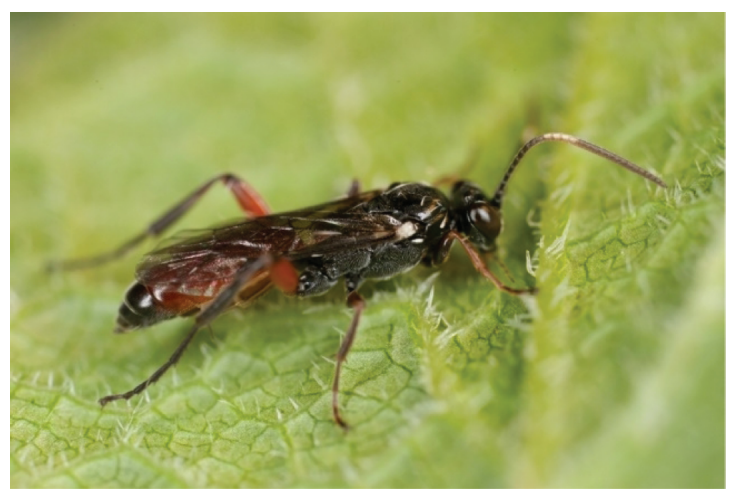

Figure 1. Insects collected and identified in this study. (a) Depressaria radiella adult; (b) Copidosoma sosares adult female; (c) Copidosoma sosares adult male; (d) 'mummy' of Depressaria radiella containing empty (eclosed) pupal exuviae of Copidosoma sosares; (e) Barichneumon heracliana adult; (f) Tyndaricus scaurus adult.

like wild parsnip, Pastinaca sativa L. (Apiales: Apiaceae) (Corbet 1970; Lee and Berenbaum 1990). Caterpillars of D. radiella feed in webs spun around umbels of hogweed plants. When they are mature, they leave the webs and crawl down the hollow, compartmentalized stems into which they chew a hole, enter the stems, and pupate. Adult moths emerge from the holes a week to $10 \mathrm{~d}$ later, mate, and females overwinter in the surrounding leaf litter. Immature stages of $D$. radiella are attacked by several species of parasitoids. The most abundant parasitoid of webworms is the specialist, polyembryonic, egg-larval parasitoid Copidosoma sosares Walker (Hymenoptera: Encyrtidae, Fig. 1b and c). Copidosoma sosares females lay either one (either a male or a female) or two (one male and one female) eggs into the webworm egg. After several rounds of polyembryonic divisions, this gives rise to all-male, all-female, or mixed-sex broods comprised of 100-300 parasitoids (Ode et al. 2004). Parasitized caterpillars form distinctive 'mummies' (Fig. 1d) that are also produced inside the hollow stems of hogweeds. Adult parasitoids emerge through the holes created by webworm larvae in the stems, mate, and the females remain in the surrounding leaf litter until the following spring. Less commonly encountered is Barichneumon heracliana Bridgman (Hymenoptera: Ichneumonidae; Fig. 1e), a specialist pupal parasitoid of D. radiella and other species in the Depressaridae. It develops in webworm pupae in host stems and emerges after several weeks, possibly overwintering as an adult. Tyndaricus (Hymenoptera: Encyrtidae) is a little studied genus containing species that are assumed to be primarily egg parasitoids or even hyperparasitoids (Gordh and Trjapitzin 1981). Tyndaricus scaurus Walker (Hymenoptera: Encyrtidae) (Fig. 1f) emerged only from C. sosares mummies, suggesting that it 
might be a hyperparasitoid, although nothing is known about its biology.

Here, in a single growing season we compared the abundance and performance of D. radiella and its (hyper)parasitoids in three separate populations of $H$. sphondylium in the Netherlands. The three plant populations are each separated by more than $100 \mathrm{~km}$ and grow in distinctly different habitats: two are riparian and grow on floodplain soils whereas the third grows well away from river floodplains. Additionally, we compared these same performance parameters in single populations of $H$. sphondylium and the invasive, allegedly more toxic giant hogweed, $H$. mantegazzianum Sommeier \& Levier (Apiales: Apiaceae), growing in close proximity at the same location. Giant hogweeds are native to the Caucaus region but were introduced as ornamental plants across western Europe over 150 yr ago where they have become abundant, highly invasive weeds (Hansen et al. 2006). Giant hogweeds also harbor D. radiella in both the native and invasive ranges (Hansen et al. 2006).

We hypothesize 1) that the performance of $D$. radiella and its parasitoids will not vary significantly in the different small hogweed populations, because all of the species are widespread and abundant in the Netherlands, thereby stabilizing selection over evolutionary time. 2) The performance of herbivores and parasitoids on the invasive giant hogweed will, however, be lower than on the native small hogweed growing in the same vicinity because of a) these insects have a longer co-evolutionary history with the native species, and b) because the native plant species is less toxic than the invader, as previous work has shown (Ode et al. 2004).

\section{Methods and Materials}

\section{Locations}

Heracelum sphondylium were sampled for D. radiella and its parasitoids from three Dutch populations in late August of 2015. The Dutch locations were a nonflood plain habitat adjacent to farmland: the northerly population in Veenhuizen, Drenthe: $53^{\circ} 2^{\prime} 38.82^{\prime \prime} \mathrm{N}$, $6^{\circ} 23^{\prime} 11.95^{\prime \prime} \mathrm{E}$; two floodplain habitats also occurring adjacent to agricultural fields: the central population in Heteren, Gelderland $51^{\circ} 57^{\prime} 17.17^{\prime \prime} \mathrm{N}, 5^{\circ} 43^{\prime} 50.97^{\prime \prime} \mathrm{E}$, and the southerly population in Drimmelen, Brabant: $51^{\circ} 42^{\prime} 24.71^{\prime \prime} \mathrm{N}, 4^{\circ} 45^{\prime} 28.88^{\prime \prime}$. All three populations were large and contained over several hundred plants or were located with several hundred meters from other populations. Climate gradients across the Netherlands are well defined (Dejonghe 2008). The most northerly population is subjected to a slightly colder conditions with fewer warm summer days $\left(\right.$ over $\left.20^{\circ} \mathrm{C}\right)$ than the others. $H$. mantegazzianum plants were sampled for D. radiella and parasitoids from a single large population in Heteren within $1 \mathrm{~km}$ of the H. sphondylium population: $51^{\circ} 57^{\prime} 14.16^{\prime \prime} \mathrm{N}, 5^{\circ} 44^{\prime} 34.63^{\prime \prime} \mathrm{E}$.

\section{Sampling of Plants for Arthropods}

Senescing plants of both species with holes perforated in stems by $D$. radiella larvae were sampled in groups of $\sim 20-30$ plants per population; most populations contained hundreds of plants with typically less than $25 \%$ infested by webworms. A fully-grown plant was defined as one in senescence; all seeds were dried or had already fallen from the plant and the outer stem was no longer moist and green in color (e.g., postreproductive stage). Plants in each location infested with $D$. radiella were sampled in mid-late August (which coincides with pupation but not eclosion in each species) using a paring knife to cut open the stems along their entire length. Each hollow stem contains several chambers that are separated by a thick wall, and all of these were opened on the sampled plants. Once a stem was cut open, it was carefully split lengthways to avoid crushing moth pupae or mummified webworm larvae containing parasitoids. These were collected from individual plants, counted, and returned to the laboratory to allow adult moths or parasitoids to emerge.

\section{Adult Moth and Parasitoid Abundance and Body Mass}

In the laboratory, pupae of D. radiella from the different plant populations were placed in Petri dishes (12 cm dia.) that were labeled with the following information: plant population (Veenhuizen, Heteren, or Drimmelen), plant individual, and plant species (H. sphondylium or H. mantegazzianum). Because it is polyembryonic and therefore gregarious, mummies containing $C$. sosares both within and between plant populations were kept singly in labeled Petri dishes.

Depressaria radiella pupae and parasitoid mummies were kept in a walk-in climate room at a temperature of $22 \pm 2{ }^{\circ} \mathrm{C}$ under a 16:8 (L:D) h regime with a 50\% r.h. until eclosion. Emerging adult moths or $B$. heracliana wasps from each of the populations or plant species were counted, anesthetized using $\mathrm{CO}_{2}$ and weighed on a Mettler-Toledo (Columbus, OH, USA) MT5 Electrobalance (accuracy $\pm 1 \mu \mathrm{g}$ ). Males and females of these two species are virtually indistinguishable so body masses were made independent of offspring sex. Parasitoids (C. sosares and T. scaurus) emerging from mummies were sexed (to determine the sex ratio) and counted. From each mummy five male and five female C. sosares were randomly removed (or only males or females in single-sex broods), killed by freezing, and weighed on the microbalance.

\section{Statistical Analysis}

To compare whether the number of $D$. radiella colonizing a stem were similar across the three Dutch locations, as well as for the two species, the number of pupae and mummified pupae were combined per stem (log-transformed) and analyzed using a general linear model with location/species as a fixed factor. To determine whether the relative numbers of pupae and mummies per stem, as well as their fate were similar in small hogweed plants sampled at the three locations, tests of independence were performed (G-tests). Fate was recorded as frequencies of dead pupae, adult eclosion from pupa (moth or B. heracliana), dead mummies (in which no wasps emerged) and parasitism by C. sosares/T. scaurus. Similarly, relative frequencies were compared for small and giant hogweed stems with holes sampled at Heteren.

To investigate whether adult masses of $D$. radiella were similar across the locations of the small hogweeds, masses were analyzed for each insect species separately with a general linear mixed model. Location was entered as a fixed factor and plant individual as a random factor (sometimes more insects of the same species were found in a single plant stem). Brood sizes of C. sosares were analyzed using a similar approach with wasp sex and brood type (allmale, all-female, and mixed) entered as additional factors in the model. When the effect of plant location was significant, TukeyKramer tests were used to conduct pair-wise comparisons of the least squared means. Data on biomass of C. sosares were analyzed separately for males and females. We used a mixed model as described before with mummy nested within plant individual as an additional random factor (many wasps develop from a single mummy). The variables above were also analyzed comparing data obtained from small and giant hogweeds using similar analyses as for the location comparisons, but with plant species as a main factor. In addition, mass of adult $B$. heracliana was compared using a general linear 
model with plant species as a main factor. This pupal parasitoid was primarily found in hogweeds growing at the Heterern location. Only two pupae were found at the two other locations, one at each site.

All analyses were performed using SAS/STAT software, version 9.4, except for the G-test which was performed manually (Sokal and Rohlf 1995)

\section{Results}

The combined numbers of D. radiella pupae and C. sosares mummies that were collected per perforated hogweed stem were similar across the locations $\left(F_{2,53}=1.05, P=0.35\right)$ and between the two hogweed species at the Heteren location $\left(F_{2,41}=0.12, P=0.73\right)$. The number of $D$. radiella pupae per plant stem varied been 1 and 21 (median 4). However, the number of pupae versus the number of mummies, as well as the emergence of other parasitoids from them (or precocious death) differed across the three locations (numbers: G-test, $\chi^{2}=19.3, \mathrm{df}=2, P<0.001$, fate of pupae: $\chi^{2}=31.7, \mathrm{df}=2$, $P<0.001$; fate of mummies: $\left.\chi^{2}=14.8, \mathrm{df}=2, P<0.001\right)$. At the Veenhuizen site, we found more pupae than mummies, whereas at the other two locations this was reversed (Fig. 2). Moreover, significantly more moths and parasitoids eclosed successfully from the pupae and mummies, respectively, collected at Veenhuizen (Fig. 2). In Heteren, the incidence of parasitism by $B$. heracliana was higher than at Veenhuizen and Drimmelen (Fig. 2). Also, the number of pupae versus mummies collected from small and large hogweeds at the Heteren location differed $\left(\chi^{2}=21.6, \mathrm{df}=2, P<0.001\right.$, Fig. 2 ). Parasitism by $C$. sosares was two-fold less in large hogweeds than

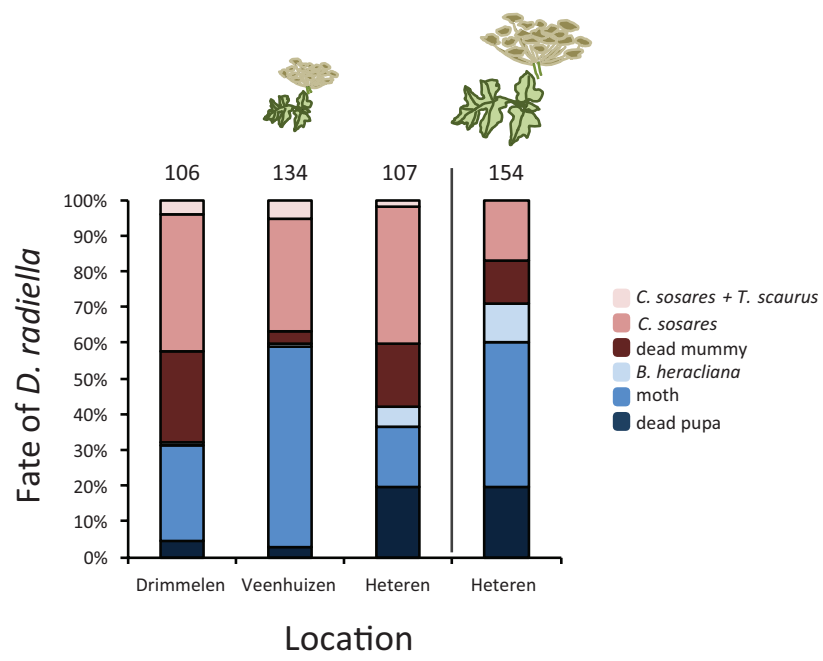

Figure 2. Fate of Depressaria radiella found in the stems of native small and invasive large hogweeds (Heracleum sphondylium and H. mantegazzianum, respectively). Small hogweeds were sampled at three locations (Veenhuizen, Heteren, and Drimmelen) (the left three bars), whereas large hogweeds were only sampled at Heteren (the right most bar), the only location where the two species were growing in close proximity. Fate of the larvae was recorded as adult moth eclosion, parasitized by the solitary pupal parasitoid Barichneumon heracliana, dead pupa, parasitized by the polyembryonic endoparasitoid Copidosoma sosares, mummies of $C$. sosares producing the potential hyperparasitoid Tyndaricus scaurus, or dead mummies. Fate is presented as percent of the total combined number of pupae and mummies collected from (20-30) perforated stems per location/species. Top three segment in each bar refer to the fate of the pupae and bottom three segments refer to the fate of the mummies. Numbers of $D$. radiella found in small hogweed stems at each location and in large hogweed at Heteren are shown above the bars. in small hogweeds (Fig. 2). The fate of the pupae also differed depending on hogweed species $\left(\chi^{2}=5.13, \mathrm{df}=1, P=0.014\right)$, whereas the fate of the mummies did not $\left(\chi^{2}=1.52, \mathrm{df}=1, P=0.15\right)$. More $D$. radiella moths and $B$. heracliana parasitoids eclosed from the giant than from the small hogweeds in Heteren. None of the mummies collected from large hogweeds produced T. scaurus. However, this species emerged from 5 to $15 \%$ of C. sosares mummies in the three small hogweed populations.

Body mass of adult $D$. radiella moths developing from small hogweeds were similar at the three locations $\left(F_{2,43.3}=2.16, P=0.12\right.$ : Fig. 3). However, moths developing from small hogweeds were larger than those developing from giant hogweeds in Heteren $\left(F_{1}\right.$, $45.3=6.12, P=0.017$; Fig. 3 ).

In total, 28,571 adult C. sosares parasitoids emerged from all sampled mummies, and 715 individuals were weighed, for the analyses. There were both plant-population and -species effects. For example, adult body masses of female adult C. sosares wasps differed depending on the location of the small hogweed plants $\left(F_{2}\right.$, ${ }_{41.4}=8.15, P<0.001$; Fig. 4a). Female wasps were heavier when emerging from mummies at the Drimmelen than at the Veenhuizen and Heteren small hogweeds (Tukey-Kramer tests, $P<0.05$ ). For the males the effect of location was not significant $\left(F_{2,25.7}=3.06\right.$, $P=0.06$; Fig. 4a). Body masses did not differ for wasps emerging from small and giant hogweed at the Heteren location (females: $F_{1}$, ${ }_{22}=0.26, P=0.61$; males $\left(F_{1,12.1}=0.29, P=0.60\right.$; Fig. $\left.4 \mathrm{a}\right)$. Females were larger than males (paired t-test for mean male and female body mass from mixed broods $\left(t_{22}=12.8, P<0.001\right)$. Broods of $C$. sosares can result in all-female, all-male or mixed broods. The number of wasps emerging from the different brood types differed (effect of broodtype: location analysis $F_{2,127}=3.26, P=0.04$; species analysis $F_{2,40.8}=5.1, P=0.01$. These differences in brood sizes were similar at the three locations (broodtype bylocation: $F_{4,118}=0.27, P=0.90$ ) and for the two plant species (broodtype by species: $F_{2,32.7}=1.85$, $P=0.17$ ) (Fig. 4b). All-female broods produced lower number of

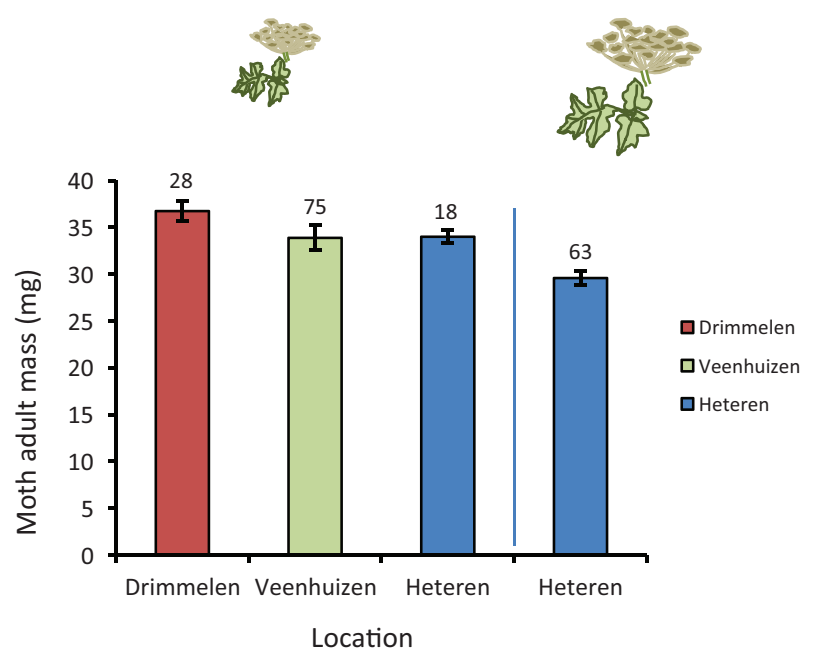

Figure 3. Mass (mean \pm se) of adult Depressaria radiella moths collected from small hogweed and large hogweed stems. Small hogweeds were sampled at three locations (Heteren, Drimmelen and Veenhuizen with 20-30 perforated stems per location), whereas the large hogweed was only sampled at Heteren, the only location where the two species were growing in close proximity. Numbers of $D$. pastinacella adults eclosing from pupae found in small hogweed stems at each location and in large hogweed at Heteren are shown above the bars. 

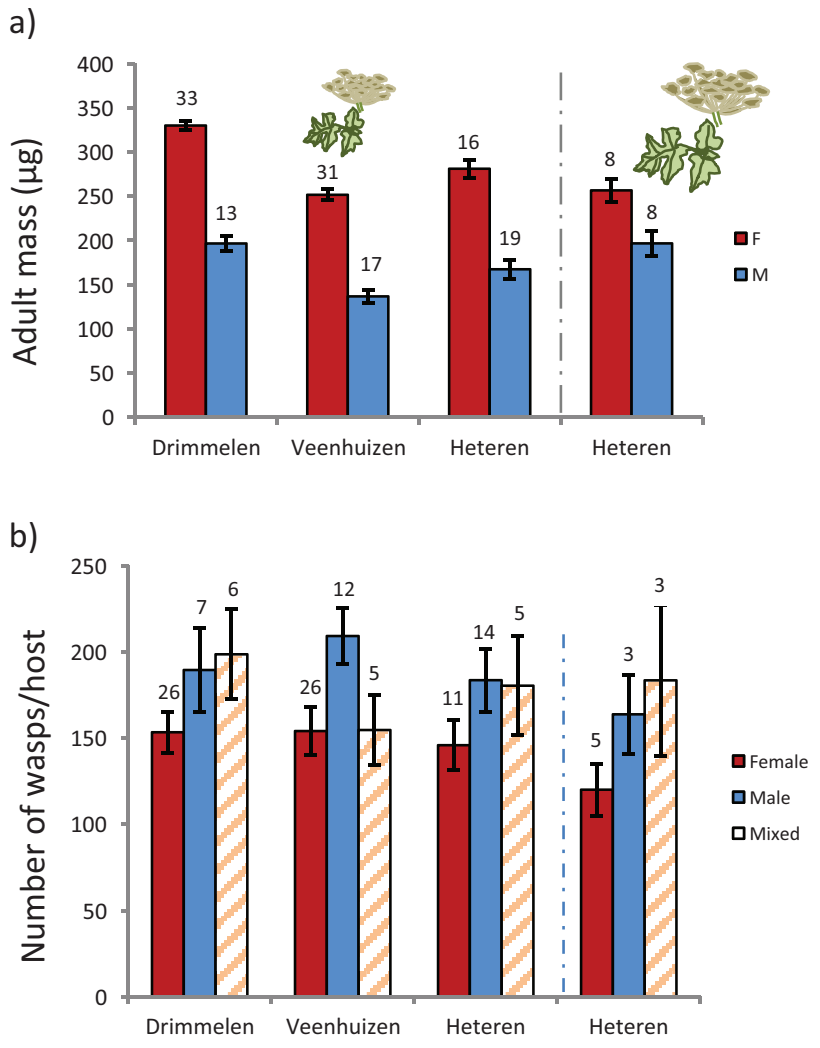

Location

Figure 4. (a) Body mass (mean \pm se) of adult female or male Copdiosoma sosares and (b) mean brood size of $C$. sosares (mean $\pm \mathrm{se}$ ) emerging from allfemale, all-male, or mixed broods collected from small hogweed and large hogweed stems. Small hogweeds with perforated stems were sampled at three locations (Heteren, Drimmelen, and Veenhuizen), whereas the large hogweed was only sampled at Heteren, the only location where the two species were growing in close proximity. From each mummy, five eclosing males, females or both in mixed-broods were weighed. The numbers of mummies that were used for weighing biomass (all-female, all-male, and mixed broods, respectively) are given above the bars.

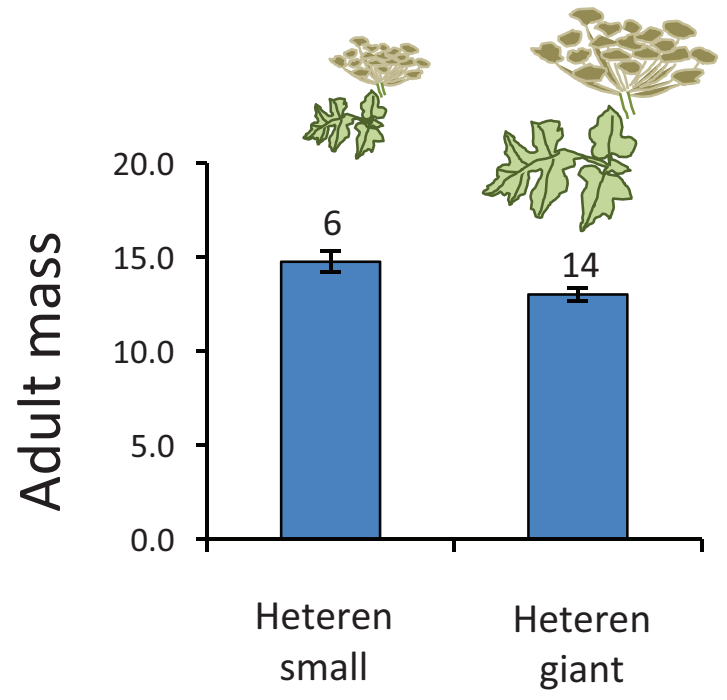

Figure 5: Adult body mass (mean $\pm \mathrm{se}$ ) of the pupal parasitoid Barichneumon heracliana developing from Depressaria pastinacella pupae collected from small hogweed and giant hogweed stems at Heteren. Sample sizes are given above the bars. wasps than all male broods, whereas brood sizes in mixed broods were more variable.

The pupal parasitoid $B$. heracliana was most abundant from both hogweed species in Heteren; only one pupa was parasitized by this parasitoid at each of the other two small hogweed populations. Adult wasps were significantly heavier when developing in host pupae collected from small than from the giant hogweed $\left(F_{1}\right.$, ${ }_{20}=7.28, P=0.014$; Fig. 5).

\section{Discussion}

The results of this investigation show that, during a single season, the fate of the parsnip webworm, D. radiella, in terms of parasitism and pupal mortality, differed across three populations of the small hogweed, $H$. sphondylium in northern, central, and southern provinces of the Netherlands. Over $50 \%$ of larvae pupated and produced adult moths in the most northerly Dutch hogweed population (Veenhuizen), whereas more than $65 \%$ of larvae and pupae of D. radiella in Heteren were parasitized by C. sosares or B. heracliana. Pupal mortality (in which adult moths failed to emerge) was high in Heteren and low in the two other small hogweed populations. The survival of parasitoids in C. sosares mummies also varied with hogweed population, and was significantly lower in Veenhuizen that at the other two locations. The parasitoid T. scaurus emerged from mummies of C. sosares from each of the three small hogweed populations but only from mixed sex broods. Furthermore, whereas there was not a significant difference in adult body mass of $D$. radiella moths across the different hogweed populations, female C. sosares were larger in Drimmelen than in Veenhuizen and Hetern hogweeds.

Comparisons between one native $H$. sphondylium and one invasive $H$. mantgazzianum population where they grow in close proximity in Heteren revealed that significantly higher numbers of moth pupae (and lower numbers of C. sosares mummies) were present in the latter species. However, the relative proportion of pupal (moth) and mummy (parasitoid) mortality was similar in both the native and invasive hogweed species. Barichneumon haracliana was also largely confined to small and giant hogweeds at Heteren and almost absent at the other small hogweed populations, whereas T. scaurus was absent from $H$. mantegazzianum. Moreover, whereas adult moth body mass and adult mass in $B$. heracliana was lower in the giant than in the small hogweed, the body mass of C. sosares was similar in both plant species. We found that adult moths and $B$. heracliana (but not C. sosares) were smaller when developing on H. mantegazzianum, which produces significantly higher concentrations of furanocoumarins than $H$. sphondylium or another native host plant, Pastinaca sativa, in the Netherlands (Ode et al. 2004). However, this difference was not dramatic (around 10\% in the moth and parasitoid), although we did not measure other fitness correlates such as reproductive success or longevity.

Our results reveal population- and species-specific differences in the abundance and performance of D. radiella and its associated parasitoids and hyperparasitoids in the Netherlands. It is important to stress, however, that this study was only performed over a single growing season, so we have little idea how much the abundance of various species in this multitrophic food web varies over time. Differences in the abundance and performance of the parasitoids may reflect long-term predictability and stability in the various interactions. However, there is evidence of temporal variability in the abundance of $D$. radiella and its parasitoids based partially on the findings of a previous study (Harvey et al. 2016) where we compared stem occupancy of insects in herbivore-infected small hogweeds in the same plant populations. The abundance of D. radiella 
and C. sosares was similar at some sites (e.g., Veenhuizen) but very different at others (e.g., Drimmelen) in different years (J.A. Harvey, unpublished). This suggests that intensity of these interactions may change from one year to another. In this situation, it is difficult to evaluate the effects on plant defense responses and how this in turn will affect insect performance. This would require long-term studies on this system carried out over at least 5-10 yr.

Hogweeds, parsnips and related plants in the Apiaceae produce secondary compounds called furanocoumarins. Concentrations of these compounds tend to be higher in plant reproductive tissues such as flowers and seeds (Pathak et al. 1962, Berenbaum 1981, Zangerl and Berenbaum 1997, Lampert et al. 2011). Although we did not measure furanocoumarins in both hogweed species, a previous study found that four Dutch populations of giant hogweed produced significantly higher ( 4-fold) concentrations of furanocoumarins (e.g., angelicin, imperatorin, isopimpinellin, and psoralen) than ten Dutch populations of small hogweed (Ode et al. 2004). Other studies have examined the effects of xanthotoxin, a representative furanocoumarin in hogweeds, in the diet of D. radiella on fitness correlates of the herbivore and C. sosares (Ode et al. 2004, Lampert et al. 2008). A positive correlation was found between dietary concentrations of xanthotoxins in webworms and unmetabolized concentrations of these compounds in their hemolymph, although no effect was found on moth size or development time. By contrast, negative correlations between the concentrations of xanthotoxins in host diet and brood size and survival in C. sosares were found (Lampert et al. 2008). Apparently, C. sosares is unable to metabolize xanthotoxins that occur in trace amounts in host hemolymph (McGovern et al. 2006). These results suggest that the negative effects of plant chemical defenses may be amplified up the food chain. Brood sizes of C. sosares in this study and in Lampert et al. (2008) were most similar in hosts fed on diets with intermediate concentrations of xanthotoxins. Bear in mind, however, that our study was conducted with native European insects whereas the Lampert et al. (2008) study used exotic insects from an American population of a native food plant, the cow parsnip (H. maximum W. Bartrum [Apiales: Apiaceae]). Unless cross-comparisons are performed, it is impossible to accurately compare the performance of populations of these insects in the two continents because they may have evolved in response to quite different selection pressures.

One of the major differences between native (European) and invasive (North American) interactions between webworms and their food plants is that populations of hogweeds and wild parsnips in the native European range have been constantly exposed to threat of webworm attack for millennia. In contrast, in the United States, where webworms are invasive, they attack the native cow parsnip (Harvey et al. 2019) or invasive populations of wild parsnip (Lohman et al. 1996). Cow parsnips do not have a long co-evolutionary history with webworms, whereas wild parsnips were re-acquainted with webworms after at least several decades of isolation from them. The longstanding 'arms-race' between webworms and their food plants in Europe makes it difficult to elucidate the reciprocal costs of webworms on plant defense and of the plant defenses on webworm performance, and how this might in turn work its way up the food chain.

Another factor to consider in plant-webworm studies is the role played by their main parasitoid, C. sosares. This parasitoid can greatly reduce numbers of $D$. radiella in the course of a single season, although we do not know how much it affects the abundance of this herbivore over a longer period of time. The effects of parasitoids on plant fitness have been the subject of considerable debate (van Loon et al. 2000, van der Meijden and Klinkhamer 2000, Hoballah \& Turlings 2001, Gols et al. 2015). Many parasitoids develop in hosts that keep growing and feeding after they are parasitized (so-called 'koinobiont' parasitoids; Harvey 2005). Solitary koinobionts generally reduce host growth considerably compared with healthy hosts whereas gregarious koinobionts often stimulate host growth (Harvey 2005). Because it is polyembryonic and therefore gregarious, a major problem in gauging the effects of C. sosares on plant fitness is that parasitized caterpillars may grow larger than healthy ones. This was demonstrated in another association between the congener C. floridanum Ashmead (Hymenoptera: Encyrtidae) and its host Trichoplusia ni Hübner (Lepidoptera: Noctuidae) (Strand 1989). A major challenge in assessing the effects of C. sosares on plant fitness is therefore in teasing apart direct effects (i.e., on seed production of plants harboring healthy or parasitized $D$. radiella caterpillars) versus indirect effects (i.e., a reduction in the abundance of $D$. radiella that frees future generations of plants from this herbivore).

In the Netherlands, $P$. sativa is rarely used as a food plant by $D$. radiella, because $H$. sphondylium is greatly preferred (Ode et al. 2004). In contrast, in North America, where P. sativa, D. radiella, and C. sosares have been introduced, $H$. sphondylium is absent. The native $H$. maximum is sparsely distributed in the eastern United States and only relatively common locally where it harbors both $D$. sativa and C. sosares. Although $P$. sativa is an invasive pest in the eastern United States, it is still rare west of the Great Plains. However. C. sosares has primarily become established in the western United States (Carroll et al. 2007) although it now appears to be establishing in Wisconsin and Illinois. If trait-remixing can occur rapidly in hogweed or parsnip populations in the short-term presence or absence of $D$. radiella, how much might this be influenced by C. sosares? Future experiments aim to determine the degree of phenotypic matching between webworms, hogweeds, and parsnips in the native range where these species are sympatric but where there is clearly a preference for H. sphondylium by D. radiella.

\section{Acknowledgments}

The authors wish to thank Charlie, our little dog who accompanied us on field collecting trips. Gregor Disveld is thanked for providing facilities for experiments to be carried out in the laboratory. John Noyes is thanked for his identification of Copidosoma sosares and Tyndaricus scaurus and Gavin Broad is thanked for his identification of Barichneumon heracliana. All photos in Fig. 1 are by Tibor Bukovinszky except (a) by the senior author. There are no conflicts of interest in the paper.

\section{Data availability statement}

The data is now stored in the Dryad Digital Repository: https://doi:10.5061/ dryad.573n 5 tb $4 \mathrm{~g}$.

\section{References Cited}

Berenbaum, M. 1981. Patterns of furanocoumarin distribution and insect herbivory in the Umbelliferae: plant chemistry and community structure. Ecology 62: 1254-1266.

Berenbaum, M. 1995. Phototoxicity of plant secondary metabolites: insect and mammalian perspectives. Arch. Insect Biochem. Physiol. 29: 119-134.

Carroll, M. J., E. C. Lampert, M. R. Berenbaum, J. S. Noyes, and P. J. Ode. 2007. New records of Copidosoma sosares (Walker) (Hymenoptera: Encyrtidae), a parasitoid of the parsnip webworm (Depressaria pastinacella (Duponchel)) (Lepidoptera: Elachistidae), in western North America. J. Kan. Entomol. Soc. 80: 309-318.

Corbet, S. A. 1970. Insects on hog weed flowers: a suggestion for a student project. J. Biol. Edu. 4: 133-143. 
Dejonghe, T. 2008. Bosatlas der Nederlanden. 53ste edition. Revue belge de géographie, Wolters-Noordhoff, Groningen, Belgium.

Fürstenberg-Hägg, J., M. Zagrobelny, and S. Bak. 2013. Plant defense against insect herbivores. Int. J. Mol. Sci. 14: 10242-10297.

Godfray, H. C. J. 1994. Parasitoids: behavioral and evolutionary ecology. Princeton University Press, Princeton, NJ.

Gols, R., R. Wagenaar, E. H. Poelman, H. M. Kruidhof, J. J. A. van Loon, and J. A. Harvey. 2015. Fitness consequences of indirect plant defence in the annual weed, Sinapis arvensis. Func. Ecol. 29: 1019-1025.

Gordh, G. and V. A. Tri'a' pit's yn. 1981. Taxonomic studies of the Encyrtidae with the descriptions of new species and a new genus, vol. 93. University of California Press, Berkeley, CA.

Hansen, S., J. Hattendorf, R. Wittenberg, S. Y. Reznik, C. Nielsen, H. P. Ravn, and W. Nentwig. 2006. Phytophagous insects of giant hogweed Heracleum mantegazzianum (Apiaceae) in invaded areas of Europe and in its native area of the Caucasus. Eur. J. Entomol. 103: 387-395.

Harvey, J. A. 2005. Factors affecting the evolution of development strategies in parasitoid wasps: the importance of functional constraints and incorporating complexity. Entomol. Exp. Appl. 117: 1-13.

Harvey, J. A., R. Gols, B. Smith, and P. J. Ode. 2019. Invasive moth facilitates use of a native Food plant by other native and invasive arthropods. Ecol. Res. 34: 659-666.

Harvey, J. A., P. J. Ode, M. Malcicka, and R. Gols. 2016. Short-term seasonal habitat facilitation mediated by an insect herbivore. Basic Appl. Ecol. 17: 447-454.

Heil, M. 2014. Herbivore-induced plant volatiles: targets, perception and unanswered questions. New Phytol. 204: 297-306.

Hoballah, M. E. F. and T. C. J. Turlings. 2001. Experimental evidence that plants under Caterpillar attack may benefit from attracting parasitoids. Evol. Ecol. Res. 3: 583-593.

Karban, R., and I. T. Baldwin. 1997. Induced responses to herbivory. University of Chicago Press, Chicago, IL.

Karban, R., A. A. Agrawal, J. S. Thaler, and L. S. Adler. 1999. Induced plant responses and information content about risk of herbivory. Trends Ecol. Evol. 14: 443-447.

Lampert, E. C., A. R. Zangerl, M. R. Berenbaum, and P. J. Ode. 2008 Tritrophic effects of xanthotoxin on the polyembryonic parasitoid Copidosoma sosares (Hymenoptera: Encyrtidae). J. Chem. Ecol. 34: 783-790.

Lampert, E. C., A. R. Zangerl, M. R. Berenbaum, and P. J. Ode. 2011. Generalist and specialist host parasitoid associations respond differently to wild parsnip (Pastinaca sativa) defensive chemistry. Ecol. Entomol. 36: $52-61$.

Lee, K., and M. R. Berenbaum. 1990. Defense of parsnip webworm against phototoxic furanocoumarins: role of antioxidant enzymes. J. Chem. Ecol. 16: 2451-2460.

Lohman, D. J., A. R. Zangerl, and M. R. Berenbaum.1996. Impact of floral herbivory by parsnip webworm (Oecophoridae: Depressaria pastinacella Duponchel) on pollination and fitness of wild parsnip (Apiaceae: Pastinaca sativa L.). Am. Midland Nat. 136: 407-412.

van Loon, J. J. A., J. G. de Boer, and M. Dicke. 2000. Parasitoid-plant mutualism: parasitoid attack of herbivore increases plant reproduction. Entomol. Exp. Appl. 97: 219-227.

Loxdale, H. D., G. Lushai, and J. A. Harvey. 2011. The evolutionary improbability of 'generalism' in nature, with special reference to insects. Biol. J. Linn. Soc. 103: 1-18.

van der Meijden, E., and P. G. L. Klinkhamer. 2000. Conflicting interests of plants and the natural enemies of herbivores. Oikos 89: 202-208.

McGovern, J. L., A. R. Zangerl, P. J. Ode, and M. R. Berenbaum.2006. Furanocoumarins and their detoxification in a tri-trophic interaction. Chemoecology 16: 45-50.

Ode, P. J., M. R. Berenbaum, A. R. Zangerl, and I. C. W. Hardy. 2004. Host plant, host plant chemistry and the polyembryonic parasitoid Copidosoma sosares: indirect effects in a tritrophic interaction. Oikos 104: 388-400.

Pathak, M. A., F. Daniels Jr., and T. B. Fitzpatrick. 1962. The presently known distribution of furanocoumarins (psoralens) in plants. J. Invest. Dermatol. 39: 225-239.

Sokal, R.R., and F. J. Rohlf. 1995. Biometry - the principles and practice of statistics in biological research, 3rd edn. W.H. Freeman and Co., New York.

Strand, M. R. 1989. Development of the polyembryonic parasitoid Copidosoma floridanum in Trichoplusia ni. Entomol. Exp. Appl. 50: 37-46.

Zangerl, A. R., and M. R. Berenbaum. 1997. Cost of chemically defending seeds: furanocoumarins and Pastinaca sativa. Am. Nat. 150: 491-504.

Zangerl, A. R. and J. K. Nitao. 1998. Optimal defence, kin conflict and the distribution of furanocoumarins among offspring of wild parsnip. Evol. Ecol. 12: 443-457.

Zych, M. 2007. On flower visitors and true pollinators: the case of protandrous Heracleum sphondylium L. (Apiaceae). Plant Syst. Evol. 263: 159-179. 